\title{
Adenocarcinoma of oesophagus: what exactly is the size of the problem and who is at risk?
}

\section{J Lagergren}

Gut 2005;54(Suppl I):i1-i5. doi: 10.1136/gut.2004.041517

The incidence of oesophageal adenocarcinoma is increasing and the prognosis is poor. There is a strong predominance of white males, and heredity plays a minor role. The established risk factors are Barrett's oesophagus, gastro-oesophageal reflux, and obesity. Infection with Helicobacter pylori and use of non-steroidal antiinflammatory drugs might reduce the risk. Medications that relax the lower oesophageal sphincter might contribute to increasing the risk. Among dietary factors, low intake of fruit, vegetables, and cereal fibres seem to increase the risk of oesophageal adenocarcinoma. The role of tobacco smoking is probably limited and alcohol consumption is not a risk factor. It is uncertain which factors cause the increasing incidence. Increasing prevalences of reflux and obesity, and decreasing prevalence of $H$ pylori infection may contribute to this development; however, the sex distributions of these factors do not match the incidence trends well. Endoscopic surveillance for oesophageal adenocarcinoma among persons with reflux and obesity is discussed, but presently there is no evidence that strongly supports such a strategy.

Correspondence to: Professor J Lagergren, Department of Surgical Sciences, Karolinska Institutet, Karolinska University Hospital, SE 17176 Stockholm, Sweden; jesper. lagergren@kus.se

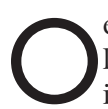
esophageal adenocarcinoma is a highly lethal cancer. Survival rates have improved during recent years in some countries, ${ }^{12}$ but the 5 year survival is still only about $10 \%$ in most Western populations. ${ }^{3}$ These poor survival rates indicate that all attempts to improve the treatment have only to a limited degree contributed to an improved overall survival. ${ }^{2}$ Some authors have reported a better survival rate among patients with cancer coming from a Barrett's mucosa ${ }^{45}$ compared with oesophageal malignancies without this metaplasia. This might be explained by more prevalent symptoms of gastro-oesophageal reflux in the Barrett's group, leading to earlier gastroscopy and confirmation of the diagnosis at an earlier tumour stage. Furthermore, the recent introduction of endoscopic surveillance programmes among patients with Barrett's mucosa in many endoscopy units might improve the long term survival in this defined group of patients. To reduce the mortality in oesophageal adenocarcinoma, it is important to identify risk factors that might make primary prevention possible (see table 1).

\section{INCIDENCE TRENDS}

The epidemiology of oesophageal adenocarcinoma is changing. Before the mid 1970s, the incidence of adenocarcinoma of the oesophagus seems to have represented less than $5 \%$ of all oesophageal cancers. Thereafter, the incidence of adenocarcinoma of the oesophagus has increased rapidly in the United States ${ }^{6-11}$ and in large parts of Europe, ${ }^{12-16}$ and is still rising. ${ }^{17}$ The reported increase among men ranged from 1.5 to $17 \%$ per year in these studies. In the white male population of the USA the reported annual increase has been close to $10 \%$, which exceeds that of any other malignancy in that population. ${ }^{8}$ In some countries the incidence of the adenocarcinoma type is higher than that of oesophageal squamous cell carcinoma. ${ }^{11}$ The increasing incidence of adenocarcinomas is not likely to be explainable by changes in diagnostic methods, with general introduction of endoscopy, because the trend differs distinctly between males and females. Furthermore, the incidence is still increasing during a period of no or minimal changes in diagnostic procedures. This increasing trend can not be explained by changes in classification of the tumours located near to or in the gastro-oesophageal junction (the tumours classified as oesophageal instead of gastrooesophageal) either because the increasing incidence is evident both in adenocarcinoma of the oesophagus and adenocarcinoma of the gastric cardia. The reasons for the increasing incidence are still unknown, but important clues have recently been found. These clues are discussed below.

Although the incidence of adenocarcinoma of the oesophagus has increased, it is still a rare disease. In countries in which population based incidence figures are available, the number of new cases per 100000 white males during year 2000 varied between 1 and $5 .{ }^{17}$ The incidence of oesophageal adenocarcinoma is highest in Great Britain; and thereafter Australia, The Netherlands, and the United States are relatively high incidence populations. Low incidence areas include countries in Eastern Europe and in Scandinavia.

\section{AGE, SEX, AND RACE DISTRIBUTION}

The age distribution is similar to most other gastrointestinal cancers, with an increased risk with increasing age. The median age at diagnosis is about 60 years. An unexplained feature of the

Abbreviations: BMI, body mass index NSAID, nonsteroidal anti-inflammatory drug; COX-2, cyclooxygenase 2 


\begin{tabular}{|c|c|}
\hline Risk factor & $\begin{array}{l}\text { Adenocarcinoma of } \\
\text { the oesophagus }\end{array}$ \\
\hline Heredity & 0 \\
\hline Male sex & ++ \\
\hline Age & ++ \\
\hline Reflux & +++ \\
\hline Cholecystectomy & + \\
\hline $\begin{array}{l}\text { Lower oesophageal sphincter- } \\
\text { relaxing medications }\end{array}$ & ++ \\
\hline Obesity & +++ \\
\hline Helicobacter pylori & -- \\
\hline Human papillomavirus & 0 \\
\hline Smoking & + \\
\hline Alcohol & 0 \\
\hline Fruits and vegetables & -- \\
\hline Antioxidants & -- \\
\hline Cereal fibre & - \\
\hline \multicolumn{2}{|c|}{$\begin{array}{l}+++ \text {, Strong positive association; }++ \text {, moderate positive } \\
\text { association; }+ \text {, weak positive association; } 0 \text {, no association } \\
-, \text { weak negative association; }--, \text { moderate negative } \\
\text { association. }\end{array}$} \\
\hline
\end{tabular}

incidence of oesophageal adenocarcinoma is the striking male predominance $(7: 1)$. This observation has been similar in all populations studied..$^{813} 16$ The incidence of oesophageal adenocarcinoma is higher among whites compared with blacks. $^{811}$ Differences in socioeconomic variables might explain this observation. ${ }^{11}$

\section{RISK FACTORS \\ Heredity}

Although familial clustering of both Barrett's oesophagus and oesophageal adenocarcinoma occurs, ${ }^{18-24}$ the influence of genetic factors in the aetiology of oesophageal adenocarcinoma seems to be of limited importance among cases occurring in the community at large. In three population based studies of familial occurrence, no evidence of family history of digestive cancer among cases of oesophageal adenocarcinoma was found. ${ }^{25-27}$ Hence, the aetiology of oesophageal adenocarcinoma is dominated by non-genetic risk factors. Moreover, the recent increase in incidence of oesophageal adenocarcinoma is not related to hereditary factors because a change of gene pool in 20-30 years is unlikely.

\section{Barrett's oesophagus and gastro-oesophageal reflux} The strongest risk condition for oesophageal adenocarcinoma is Barrett's oesophagus. Barrett's oesophagus is an acquired condition secondary to long standing gastro-oesophageal reflux disease. ${ }^{28}$ Patients with this premalignant mucosa have an excess risk of developing adenocarcinoma ranging between 30 - and 400 -fold. ${ }^{29-35}$ In studies with a large sample size, the excess risk has been estimated to be 30 - to 60 -fold relative to the risk of the general population..$^{29} 303335$ A majority of cases with adenocarcinoma of the oesophagus arise from a Barrett's mucosa. ${ }^{36}$ The role of gastro-oesophageal reflux (or reflux symptoms) per se in the development of oesophageal adenocarcinoma has been investigated in four recent large epidemiological studies. In a medical record based case control study including 196 patients with oesophageal or cardia adenocarcinoma in the United States, a significantly twofold increased risk was found among persons with a recorded history of gastro-oesophageal reflux disease, hiatus hernia, oesophagitis/oesophageal ulcer, or difficulty in swallowing. ${ }^{37}$ In a Swedish population based, nationwide case control study, information on subjects' history of gastrooesophageal reflux was collected during personal inter- views. $^{38}$ One hundred and eighty nine patients with oesophageal adenocarcinoma and 820 control subjects were interviewed. Among persons with recurrent symptoms of reflux occurring at least once per week, the risk of oesophageal adenocarcinoma was eightfold increased. The more frequent, more severe, and longer lasting the symptoms of reflux, the greater the risk. Among persons with longstanding and severe symptoms of reflux, the odds ratio (OR) was 43.5 for oesophageal adenocarcinoma. In a case control study of similar design in the United States, there was also a dose response relation between reflux symptoms and oesophageal adenocarcinoma; ${ }^{39}$ however, the relative risk estimates were not as high as in the Swedish study. A recent population based study of the relation between gastrooesophageal reflux disease and oesophageal adenocarcinoma used a cohort design. ${ }^{40}$ A cohort of 65000 male patients with a discharge diagnosis of heartburn, hiatus hernia, or oesophagitis was identified in the Swedish Inpatient Register. Virtually complete follow up was attained through record linkage with several nationwide registers, and 37 cases of oesophageal adenocarcinomas were identified. There was a ninefold increased risk of oesophageal adenocarcinoma among patients with an endoscopically verified oesophagitis. The risk estimates increased with increasing follow up time ( $p$ for trend $=0.03$ ). Based on all these four studies, it is possible to establish that reflux is a major risk factor for oesophageal adenocarcinoma.

\section{Lower oesophageal sphincter relaxing drugs}

Data from a Swedish case control study support that a continuous and long standing use of medications that can relax the lower oesophageal sphincter, and thereby cause gastro-oesophageal reflux, increases the risk of developing adenocarcinoma of the oesophagus. ${ }^{41}$ Groups of medications that were introduced before the increase in incidence of oesophageal adenocarcinoma started included nitroglycerins, aminophylline, $\beta$ receptor agonists, anticholinergics, and benzodiazepines. A use of any of the medications in these five groups for more than 5 years increased the risk of oesophageal adenocarcinoma significantly and more than twofold. After adjustment for reflux symptoms, this association disappeared, indicating that the mechanism behind the association might be reflux, as hypothesised. ${ }^{41}$ In a study from the United States, there was no clear signs of an association between drugs that can relax the lower oesophageal sphincter and risk of oesophageal adenocarcinoma. ${ }^{42}$ Therefore, the relation needs to be further studied.

\section{Body mass}

Obesity (body mass index (BMI) $>30$ ) is common in Europe and the United States, where the prevalence has been estimated at $11-15 \%$ in men and $15-25 \%$ in women. ${ }^{43} 44$ The prevalence of obesity is increasing in these parts of the world. ${ }^{43}$ A high BMI has been found to be a risk factor for adenocarcinoma of the oesophagus in several epidemiological case control studies. ${ }^{45-50}$ In a few other case control studies no association was found between BMI and the risk of either adenocarcinoma of the oesophagus or the gastric cardia. ${ }^{5152}$ The three more recent studies were of large sample size with an advantage of a population based design, and they all show similar results, which strongly indicate that there is a true and dose dependent association between increasing BMI and risk of oesophageal adenocarcinoma, independent of reflux. ${ }^{48-50}$ Among persons with a historical BMI above 30 the relative risk of developing oesophageal adenocarcinoma has been found to be as high as 16 compared with the leanest $(\mathrm{BMI}<22)$. The mechanism behind this association remains to be identified. 


\section{Tobacco smoking}

Eight case control studies have reported a moderately increased risk of adenocarcinoma of the oesophagus and/or the gastric cardia among tobacco smokers (cigarette smoking), with ORs of generally about $1.5-2.8 .{ }^{46}{ }^{50-56}$ In three studies no association between smoking and oesophageal adenocarcinoma was found. ${ }^{57-59}$ Among all these studies, there are three large scale studies of population based design that might be considered to be of higher internal validity as compared with the other studies. ${ }^{505659}$ The two US studies found moderately increased risk of adenocarcinoma of the oesophagus among tobacco smokers, ${ }^{50}{ }^{56}$ but no significant association was identified in a Swedish study..$^{59}$ Taken together, any association with smoking seems to be of moderate strength.

\section{Alcohol drinking}

In three studies in which adenocarcinomas of the oesophagus and gastric cardia were combined, there was a positive association with alcohol, ${ }^{46}{ }^{51}{ }^{54}$ but in one other corresponding study there was not. ${ }^{25}$ None of the five studies that addressed the relationship between alcohol consumption and the risk specifically of adenocarcinoma of the oesophagus revealed a positive association..$^{50-59}$ Three large population based case control studies have probably provided the most reliable results hitherto concerning the influence of alcohol.505659 Based on data from all these studies, it may be concluded that alcohol is not associated with an increased risk of oesophageal adenocarcinoma, independent of the type of alcoholic beverage consumed.

\section{Helicobacter pylori}

Evidence of an inverse relation on the individual level between Helicobacter pylori infection and risk of adenocarcinoma of the oesophagus or gastro-oesophageal junction is accumulating. ${ }^{60-65}$ In a case control study by Chow et al, it was found that infection with $H$ pylori as measured by positive results for both IgG serology and cagA positivity (ELISA) significantly decreased the risk of oesophageal or cardia adenocarcinoma by $60 \%$. Similarly, a Swedish population based study revealed that regardless of whether IgG ELISA, CagA, or both were used as indicator of infection, there was a significantly $50-80 \%$ reduced risk for oesophageal adenocarcinoma. ${ }^{65} \mathrm{~A}$ study of similar design by Wu et al, revealed no association between $H$ pylori infection and oesophageal adenocarcinoma. ${ }^{66}$ The postulated mechanism for the alleged protective effect of $\mathrm{H}$ pylori is through its ability to introduce atrophic gastritis, and possibly also by increasing intragastric ammonia production. ${ }^{67}$ This mechanism was recently challenged in the Swedish case control study though because the inverse association between $H$ pylori and oesophageal adenocarcinoma remained unaffected after adjustment for gastric atrophy. ${ }^{65}$

\section{Diet}

There are a few known dietary risk factors. ${ }^{68}$ The best established risk exposure is low intake of fruit and vegetables. ${ }^{69} 70$ Particularly, the antioxidants in these dietary items seem to have a protective effect. ${ }^{69} 71$ Furthermore, low intake of fibres seems to increase the risk according to two large population based case control studies. ${ }^{69} 72$ Other potential dietary risk factors include high intake of dietary fat, dietary cholesterol, and animal protein. ${ }^{69}$ The data concerning diet and oesophageal adenocarcinoma are limited and susceptible to bias, particularly the role of confounding by dietary variables, which is a source of error that is difficult to reliably adjust for. Therefore, more well designed studies are needed to establish new dietary risk factors.

\section{Non-steroidal anti-inflammatory drugs}

Multiple studies furthermore have indicated an antitumoural effect on gastrointestinal tumours by the use of non-steroidal anti-inflammatory drugs (NSAIDs), especially by using selective cyclooxygenase-2 (COX-2) inhibitors. ${ }^{73}{ }^{74}$ Over representation of COX-2 has been identified in oesophageal cancer of both the squamous cell carcinoma and the adenocarcinoma type. ${ }^{75-77}$ Tumour growth in oesophageal cancer is reduced by the treatment with COX-2 inhibitors. ${ }^{78}$ Epidemiological studies have shown a reduced risk of developing oesophageal cancer among individuals using NSAID drugs. ${ }^{79-81}$ Therefore, data are accumulating in the direction of a protective effect of NSAIDs.

\section{EXPLANATIONS FOR THE CHANGING EPIDEMIOLOGY}

Although gastro-oesophageal reflux is the strongest known risk factor for oesophageal adenocarcinoma, it is uncertain whether this factor contributes to the increasing incidence of this tumour. If reflux would be the main reason for the increasing incidence of oesophageal adenocarcinoma, the incidence of reflux disease should have risen during recent decades. There is unfortunately a lack of data on the incidence of gastro-oesophageal reflux disease. The only available measure of the occurrence of reflux is prevalence figures. In a study of hospitalisation for reflux disease, the prevalence of diagnoses representing gastro-oesophageal reflux had increased during the period in which the incidence of adenocarcinoma of the oesophagus had increased. ${ }^{82}$ The main problem with the study was that the recording of reflux disease in the medical records might not mirror the true incidence of the disease. In that sense, it might be more appropriate to evaluate the prevalence of reflux symptoms in population based studies. According to such studies, there are no clear signs of an increasing prevalence in earlier studies when compared with more recent ones. ${ }^{38}{ }^{83-85}$ Hence, there are as yet no data to firmly support an increasing incidence of reflux disease. If the incidence of reflux is rising, this increase in turn should be caused by some environmental factor. Such a potential environmental factor is the use of medications that relax the lower oesophageal sphincter and thereby facilitate reflux. As discussed above, a positive association between previous use of such medications and the risk of oesophageal adenocarcinoma has been identified. ${ }^{41}$ Another study of similar design in the United States showed conflicting results. ${ }^{42}$ The increasing use of these drugs in the 1960s and 1970s may still have contributed to the increase in incidence of oesophageal adenocarcinoma.

It would be tempting to attribute the increase in the incidence of oesophageal adenocarcinoma to the increase in average body mass observed in Western populations, especially in men. ${ }^{43}$ However, the apparently sudden deflection of the incidence curve for oesophageal adenocarcinoma, ${ }^{9}$ the rapidity of the increase, ${ }^{11}$ and the marked (6-8-fold) male predominance $^{11}$ are observations not entirely consistent with this interpretation.

Tobacco smoking has been proposed to be a risk factor contributing to the rising incidence of adenocarcinoma of the oesophagus. ${ }^{56}$ However, the association between smoking and squamous cell carcinoma of the oesophagus is much stronger than that with adenocarcinoma. ${ }^{505659}$ Moreover, the association has been refuted in some studies of high validity. ${ }^{59}$ Furthermore, smoking has declined markedly among men, as reflected by a decreasing incidence of lung cancer $^{86}$; the increasing incidence of oesophageal adenocarcinoma has been practically confined to men. ${ }^{11}$ Taken together, tobacco smoking does not seem to be the main reason for the increasing incidence of these tumours. 
It has been suggested that this increase is linked to falling rates of $\mathrm{H}$ pylori infection in Western society. ${ }^{60}$ The majority of data point to the idea that there is a true inverse relationship between infection with $H$ pylori and risk of oesophageal adenocarcinoma, but more studies are warranted to establish these preliminary findings.

In conclusion, gastro-oesophageal reflux, the use of medications that might cause such reflux, obesity, and the decreasing occurrence of infection with $H$ pylori might all be key factors to explain the increasing incidence of adenocarcinoma of the oesophagus. A general problem with any explanation for the increasing incidence of oesophageal adenocarcinoma based on the known risk factors for the disease presented above is the skewed sex distribution that does not match any of the major risk factors. Hence, the mysterious epidemiology of this cancer is not yet solved.

\section{A NEED FOR SCREENING OR SURVEILLANCE}

Because the poor survival rates for adenocarcinoma of the oesophagus ${ }^{3}$ are improved only by early tumour detection, ${ }^{87}$ it is important to identify high risk people in whom endoscopic screening or surveillance might be warranted. However, because reflux symptoms are common ${ }^{83}$ and oesophageal adenocarcinoma is still a rare disease, endoscopic screening in reflux patients would rapidly overtax available healthcare resources. ${ }^{38}$ The possible benefits of endoscopic screening should exceed the costs and inconveniences for patients and healthcare systems. In a re-analysis of Swedish nationwide case control data, we estimated the number of endoscopies needed to identify one oesophageal or cardia adenocarcinoma in people with various combinations of both obesity and reflux. ${ }^{88}$ Risk of oesophageal adenocarcinoma increased dose dependently with increasing BMI and reflux severity. The risks combined in a multiplicative manner. Among obese people (BMI $>30 \mathrm{~kg} / \mathrm{m}^{2}$ ) with reflux symptoms, the odds ratio was 184 (95\% CI 36 to 949$)$ for oesophageal adenocarcinoma compared with lean people (BMI $<22 \mathrm{~kg} / \mathrm{m}^{2}$ ) without reflux. We then estimated the number needed to screen to detect one oesophageal or cardia adenocarcinoma among males aged 50-79 years. Six per cent had the combination of BMI $25 \mathrm{~kg} / \mathrm{m}^{2}$ and reflux symptoms, but only $0.3 \%$ of males aged $50-79$ years had reflux and BMI $>30 \mathrm{~kg} /$ $\mathrm{m}^{2}$. The number of people needed to screen to detect one adenocarcinoma varied from 2189 in the former stratum, to 594 in the latter. Thus, if 60 obese men aged 50-79 with reflux symptoms are followed for 10 years, one oesophageal or cardia adenocarcinoma will be observed. In the United States, the incidence figures of oesophageal adenocarcinoma are higher compared with those in Sweden. According to a recent analysis based on data accrued in the gathered literature, screening endoscopy, but not surveillance, might play a role among men over 50 years with severe reflux symptoms ${ }^{89}$ In conclusion, it is possible to identify a limited group with a relative risk that greatly exceeds that of the general population. Endoscopic surveillance for oesophageal adenocarcinoma in this group would, however, consume considerable healthcare resources. Furthermore, the data to support a general recommendation in favour of surveillance are limited. Therefore, presently there is no need for surveillance programmes among people with reflux and obesity. Given the poor results of treatment of the cancer when it occurs and if the incidence of these tumours continues to increase, new studies might find that surveillance may be worthwhile in the future.

\section{REFERENCES}

1 Sundelöf $M, Y e W$, Dickman $P$, et al. Improved survival in both histological types of oesophageal cancer in Sweden. Int J Cancer 2002;99:751-4.
2 Farrow DC, Vaughan TL. Determinants of survival following the diagnosis of esophageal adenocarcinoma (United States). Cancer Causes Control 1996;7:322-7.

3 Survival of Cancer Patients in Europe: The EUROCARE II Study. Lyon: International Agency for Research on Cancer, 1999.

4 Johansson J, Johnsson F, Walther B, el al. Adenocarcinoma in the distal esophagus with and without Barrett esophagus. Differences in symptoms and survival rates. Arch Surg 1996;131:708-13.

5 Thomas $\mathrm{P}$, Doddoli $\mathrm{C}$, Lienne $\mathrm{P}$, et al. Changing patterns and surgical results in adenocarcinoma of the oesophagus. Br J Surg 1997;84:119-25.

6 Yang PC, Davis S. Incidence of cancer of the esophagus in the US by histologic type. Cancer 1988;61:612-7.

7 Hesketh PJ, Clapp RW, Doos WG, et al. The increasing frequency of adenocarcinoma of the esophagus. Cancer 1989:64:526-30.

8 Blot WJ, Devesa SS, Kneller RW, et al. Rising incidence of adenocarcinoma of the esophagus and gastric cardia. JAMA 1991;265:1287-9.

9 Pera M, Cameron AJ, Trastek VF, et al. Increasing incidence of adenocarcinoma of the esophagus and esophagogastric junction. Gastroenterology 1993;104:510-3.

10 Thomas RM, Sobin LH. Gastrointestinal cancer. Cancer 1995;75:154-70.

11 Devesa SS, Blot WJ, Fraumeni JF Jr. Changing patterns in the incidence of esophageal and gastric carcinoma in the United States. Cancer 1998:83:2049-53.

12 Möller H, Möller-Jensen O. Den tidsmaessige udvikling i esophagus-, cardiaog ventrikelcancer i Danmark 1943-1982. Kraeftstatistik nr. 19. Ugeskr Laeger 1987; 149:1904-9

13 Powell J, McConkey CC. The rising trend in oesophageal adenocarcinoma and gastric cardia. Eur $J$ Cancer Prev 1992;1:265-9.

14 Armstrong RW, Borman B. Trends in incidence rates of adenocarcinoma of the oesophagus and gastric cardia in New Zealand, 1978-1992. Int J Epidemiol 1996;25:941-7.

15 Hansen S, Wiig JN, Giercksky KE, et al. Esophageal and gastric carcinoma in Norway 1958-1992: incidence time trend variability according to morphological subtypes and organ subsites. Int J Cancer 1997;71:340-4

16 Hansson LE, Sparén P, Nyrén O. Increasing incidence in both histological types of esophageal carcinomas among men in Sweden. Int J Cancer 1993;54:402-7.

17 Bollschweiler E, Wolfgarten E, Gutschow C, et al. Demographic variations in the rising incidence of esophageal adenocarcinoma in white males. Cancer 2001;92:549-55.

18 Romero Y, Cameron AJ, Locke GR 3rd, et al. amilial aggregation of gastroesophageal reflux in patients with Barrett's esophagus and esophageal adenocarcinoma. Gastroenterology 1997;113:1449-56.

19 Chak A, Lee T, Kinnard MF, et al. Familial aggregation of Barrett's oesophagus, oesophageal adenocarcinoma, and oesophagogastric junctional adenocarcinoma in Caucasian adults. Gut 2002;51:323-8.

20 Crabb DW, Berk MA, Hall TR, et al. Familial gastroesophageal reflux and development of Barrett's esophagus. Ann Intern Med 1985; 103:52-54.

21 Prior A, Whorwell PJ. Familial Barrett's oesophagus? Hepatogastroenterology 1986:33:86-7.

22 Jochem VJ, Fuerst PA, Fromkes JJ. Familial Barrett's esophagus associated with adenocarcinoma. Gastroenterology 1992;102:1400-2.

23 Eng C, Spechler SJ, Ruben R, et al. Familial Barrett's esophagus and adenocarcinoma of the gastroesophageal junction. Cancer Epidemiol Biomarkers Prev, 1993;2:397-9.

24 Poynton AR, Walsh TN, O'Sullivan G, et al. Carcinoma arising in familial Barrett's esophagus. Am J Gastroenterol 1996;91:1855-6.

25 Zhang ZF, Kurtz RC, Sun M, et al. Adenocarcinomas of the esophagus and gastric cardia: Medical conditions, tobacco, alcohol, and socioeconomic factors. Cancer Epidemiol Biomarkers Prev 1996;5:761-8.

26 Lagergren J, Ye W, Lindgren A, et al. Heredity and risk of cancer of the esophagus and gastric cardia. Cancer Epidemiol Biomarkers Prev 2000;9:757-60.

27 Dhillon PK, Farrow DC, Vaughan TL, et al. Family history of cancer and risk of esophageal and gastric cancers in the United States. Int J Cancer 2001;93:148-52.

28 Spechler SJ, Goyal RK. Barrett's esophagus. N Engl J Med 1986;315:362-71

29 Spechler SJ, Robbins AH, Rubins HB, et al. Adenocarcinoma and Barrett's esophagus. An overrated risk. Gastroenterology 1984;87:927-33.

30 Cameron AJ, OH BJ, Payne WS. The incidence of adenocarcinoma in columnar-lined (Barrett's) esophagus. N Engl J Med 1985;313:857-8.

31 Robertson CS, Mayberry JF, Nicholson DA, et al. Value of endoscopic surveillance in the detection of neoplastic change in Barrett's oesophagus. $\mathrm{Br} J$ Surg 1988;72:760-3.

32 Hameeteman W, Tytgat GNJ, Houthoff HJ, et al. Barrett's esophagus: development of dysplasia and adenocarcinoma. Gastroenterology 1989;96:1249-56.

33 Van Der Veen AH, Dees J, Blankenstein JD, et al. Adenocarcinoma in Barrett's oesophagus: an overrated risk. Gut 1989;30:14-8.

34 Ovaska J, Miettinen M, Kivilasakso E. Adenocarcinoma arising in Barrett's esophagus. Dig Dis Sci 1989;34:1336-9.

35 Drewitz DJ, Sampliner RE, Garewal HS. The incidence of adenocarcinoma in Barrett's esophagus: a prospective study of 170 patients followed 4.8 years. Am J Gastroenterol 1997;92:212-5.

36 Kim R, Weissfeld JL, Reynolds JC, et al. Etiology of Barrett's esophagus and esophageal adenocarcinoma. Cancer Epidemiol Biomarks Prev 1997;6:369-77.

37 Chow WH, Finkle WD, McLaughlin JK, et al. The relation of gastroesophageal reflux disease and its treatment to adenocarcinomas of the esophagus and gastric cardia. JAMA 1995;274:474-7. 
38 Lagergren J, Bergström R, Lindgren A, et al. Symptomatic gastroesophageal reflux is a strong risk factor for esophageal adenocarcinoma. N Engl J Med 1999;340:825-31.

39 Farrow DC, Vaughan TL, Sweeney C, et al. Gastroesophageal reflux disease, use of $\mathrm{H} 2$ receptor antagonists, and risk of esophageal and gastric cancer. Cancer Causes Control 2000;1 1:231-8.

40 Ye W, Chow WH, Lagergren J, et al. Risk of adenocarcinomas of the oesophagus and gastric cardia in patients with gastroesophageal reflux diseases and after antireflux surgery. Gastroenterology 2001;121:1286-93.

41 Lagergren J, Bergström R, Adami HO, et al. Association between medications that relax the lower esophageal sphincter and risk for esophageal adenocarcinoma. Ann Intern Med 2000;133:165-75.

42 Vaughan TL, Farrow DC, Hansten PD, et al. Risk of esophageal and gastric adenocarcinomas in relation to use of calcium channel blockers, asthma drugs, and other medications that promote gastroesophageal reflux. Cancer Epidemiol Biomarkers Prev 1998;7:749-56.

43 Seidell JC, Flegal KM. Assessing obesity: classification and epidemiology. $\mathrm{Br}$ Med Bull 1997;53:238-52.

44 Kuszmarski RJ, Flegal KM, Campbell SM, et al. Increasing prevalence of overweight among US adults. The National Health and Nutrition Examination Surveys, 1960 to 1991. JAMA 1994;272:205-11.

45 Brown LM, Swanson CA, Gridley G, et al. Adenocarcinoma of the esophagus: role of obesity and diet. J Natl Cancer Inst 1995;87:104-9.

46 Vaughan TL, Davis S, Kristal A, et al. Obesity, alcohol, and tobacco as risk factors for cancers of the esophagus and gastric cardia: adenocarcinoma versus squamous cell carcinoma. Cancer Epidemiol Biomarkers Prev 1995;4:85-92.

47 Ji BT, Chow WH, Yang G, et al. Body mass index and the risk of cancers of the gastric cardia and distal stomach in Shanghai, China. Cancer Epidemiol Biomarkers Prev 1997;6:481-5.

48 Chow WH, Blot WJ, Vaughan TL, et al. Body mass index and risk of adenocarcinoma of the esophagus and gastric cardia. J Natl Cancer Inst 1998:90:150-5.

49 Lagergren J, Bergström R, Nyrén O. Association between body mass and adenocarcinoma of the esophagus and gastric cardia. Ann Intern Med 1999;130:883-90.

50 Wu AH, Wan P, Bernstein L. A multiethnic population-based study of smoking alcohol and body size and risk of adenocarcinomas of the stomach and esophagus (United States). Cancer Causes Control 2001;12:721-32.

51 Kabat GC, Ng SK, Wynder EL. Tobacco, alcohol intake, and diet in relation to adenocarcinoma of the esophagus and gastric cardia. Cancer Causes Control 1993:4:123-32.

52 Li JY, Ershow AG, Chen ZJ, et al. A case-control study of cancer of the esophagus and gastric cardia in Linxian. Int J Cancer 1989;43:755-61

53 Wu-Williams AH, Yu MC, Mack TM. Life-style, workplace, and stomach cancer by subsite in young men of Los Angeles county. Cancer Res 1990;50:2569-76.

54 Brown LM, Silverman DT, Pottern LM, et al. Adenocarcinoma of the esophagus and esophagogastric junction in white men in the United States: alcohol, tobacco, and socioeconomic factors. Cancer Causes Control 1994; 5:333-40.

55 Gonzalez CA, Agudo A, Montes J. Tobacco and alcohol intake in relation to adenocarcinoma of the gastric cardia in Spain. Cancer Causes Control 1994;5:88-9

56 Gammon MD, Schoenberg JB, Ahsan H, et al. Tobacco, alcohol, and socioeconomic status and adenocarcinomas of the esophagus and gastric cardia. J Natl Cancer Inst 1997:89:1277-84.

57 Levi F, Ollyo JB, Vecchia C, et al. The consumption of tobacco, alcohol and the risk of adenocarcinoma in Barrett's esophagus. Int J Cancer 1990;45:852-4.

58 Gao YT, McLaughlin JK, Blot WJ, et al. Risk factors for esophageal cancer in Shanghai, China. Role of cigarette smoking and alcohol drinking. Int J Cancer 1994:58:192-6.

59 Lagergren J, Bergström R, Lindgren A, et al. The role of tobacco, snuff and alcohol use in the aetiology of cancer of the oesophagus and gastric cardia. Int J Cancer 2000;85:340-6.

60 Chow WH, Blaser MJ, Blot WJ, et al. An inverse relation between cagA+ strains of Helicobacter pylori infection and risk of esophageal and gastric cardia adenocarcinoma. Cancer Res 1998;58:588-90.

61 Graham DY, Yamaoka Y. H. pylori and cagA: relationships with gastric cancer, duodenal ulcer, and reflux esophagitis and its complications, Helicobacter 1998;3:145-51.

62 Vieth M, Masoud B, Meining A, et al. Helicobacter pylori infection: protection against Barrett's mucosa and neoplasia? Digestion 2000;62:225-31.
63 Weston AP, Badr AS, Topalovski M, et al. Prospective evaluation of the prevalence of gastric Helicobacter pylori infection in patients with GERD, Barrett's esophagus, Barrett's dysplasia, and Barrett's adenocarcinoma. Am J Gastroenterol 2000:95:387-94.

64 Simán JH, Forsgren A, Berglund $G$, et al. H. Helicobacter pylori infection is associated with a decreased risk of developing oesophageal neoplasms. Helicobacter 2001;4:310-6.

$65 \mathrm{Ye} \mathrm{W}$, Held M, Lagergren J, et al. Helicobacter pylori infection and gastric atrophy: risk of adenocarcinoma and squamous-cell carcinoma of the esophagus and gastric cardia adenocarcinoma. J Natl Cancer Inst 2004;96:388-96.

66 Wu AH, Crabtree JE, Bernstein L, et al. Role of Helicobacter pylori CagA+ strains and risk of adenocarcinoma of the stomach and esophagus. Int J Cancer 2003;103:815-21

67 Richter JE, Falk GW, Vaezi MF. Helicobacter pylori and gastroesophageal reflux disease: the bug may not be all bad. Am J Gastroenterol 1998;93:1800-2.

68 Mayne ST, Navarro SA. Diet, obesity and reflux in the etiology of adenocarcinomas of the esophagus and gastric cardia in humans. J Nutr 2002;132:3467S-70S.

69 Mayne ST, Risch HA, Dubrow R, et al. Nutrient intake and risk of subtypes of esophageal and gastric cancer. Cancer Epidemiol Biomarks Prev 2001; 10:1055-62.

70 Terry $\mathbf{P}$, Lagergren J, Hansen $\mathrm{H}$, et al. Fruit and vegetable consumption in the prevention of esophageal and cardia cancers. Eur J Cancer Prev $2001 ; 10: 365-9$.

71 Terry P, Lagergren J, Ye W, et al. Antioxidants and cancers of the esophagus and gastric cardia. Int J Cancer 2000;87:750-4.

72 Terry $\mathbf{P}$, Lagergren J, Ye W, et al. Inverse association between intake of cereal fiber and risk of gastric cardia cancer. Gastroenterology 2001;120:387-91.

73 Taketo MM. Cyclooxygenase-2 inhibitors in tumorigenesis (Part I). J Natl Cancer Inst 1998;90:1529-36.

74 Taketo MM. Cyclooxygenase-2 inhibitors in tumorigenesis (Part II). J Nat Cancer Inst 1998;90:1609-20.

75 Wilson KT, Fu S, Ramanujam KS, et al. Increased expression of inducible nitric oxide synthase and cyclooxygenase-2 in Barrett's esophagus and associated adenocarcinomas. Cancer Res 1998;58:2929-34.

76 Zimmermann KC, Sarbia M, Weber AA, et al. Cyclooxygenase-2 expression in human esophageal carcinoma. Cancer Res 1999;59:198-204.

77 Shirvani VN, Ouatu-Lascar R, Kaur BS, et al. Triadafilopoulos G. Cyclooxygenase 2 expression in Barrett's esophagus and adenocarcinoma: ex vivo induction by bile salts and acid exposure, Gastroenterology 2000;1 18:487-96.

78 Souza RF, Shewmake K, Beer DG, et al. Selective inhibition of cyclooxygenase-2 suppresses growth and induces apoptosis in human esophageal adenocarcinoma cells. Cancer Res 2000;60:5767-72.

79 Funkhouser EM, Sharp GB. Aspirin and reduced risk of esophageal carcinoma. Cancer 1995;76:1116-9.

80 Thun MJ, Namboodiri MM, Calle EE, et al. Asperin and risk of fatal cancer. Cancer Res 1993;53:1322-7.

81 Farrow DC, Vaughan TL, Hansten PD, et al. Use of aspirin and other nonsteroidal anti-inflammatory drugs and risk of esophageal and gastric cancer. Cancer Epidemiol Biomarkers Prev 1998;7:97-102.

82 El-Serag HB, Sonnenberg A. Opposing time trends of peptic ulcer and reflux disease. Gut 1998;43:327-33.

83 Locke GR, Talley NJ, Fett SL, et al. Prevalence and clinical spectrum of gastroesophageal reflux: a population-based study in Olmsted County, Minnesota. Gastroenterology 1997; 1 12:1448-56.

84 Nebel OT, Fornes MF, Castell DO. Symptomatic gastroesophageal reflux: incidence and precipitating factors. Am J Dig Dis 1976;21:953-6.

85 Thompson WG, Heaton KW. Heartburn and globus in apparently healthy people. Canadian Medical Association Journal 1982;126:46-8.

86 Cancer Registry. Cancer incidence in Sweden 1993, 1994 and 1995. Stockholm: National Board of Health and Welfare, 1996, 1997, and, 1998.

87 Altorki NK, Skinner DB. Adenocarcinoma in Barrett's esophagus. Semin Surg Oncol 1990;6:274-8.

88 Lagergren J, Ye W, Bergström R, et al. Utility of endoscopic screening for upper gastrointestinal adenocarcinoma. JAMA 2000;284:961-2.

89 Inadomi JM, Sampliner R, Lagergren J, et al. Screening and surveillance for Barrett's esophagus in high-risk patients: a cost-utility analysis. Ann Intern Med 2003; 138:176-86 